\title{
ELEIÇÃO PRESIDENCIAL DE 2018: O FUNCIONAMENTO DO LUGAR DISCURSIVO DO PORTA-VOZ NA CAMPANHA DE TRÊS CANDIDATOS
}

\author{
Beatriz Rocha de Oliveira \\ Edvania Gomes da Silva*
}

\begin{abstract}
RESUMO: Neste artigo, objetivamos analisar como se constituem as diferentes posições-sujeito ocupadas por três candidatos à presidência do Brasil nas eleições de 2018, que se filiam, em alguma medida, à esfera religiosa, indicando quais memórias tais posições retomam. Como hipótese, defendemos que funciona, nesse caso, o lugar discursivo do porta-voz e, por isso, buscamos identificar, a partir das posições por meio das quais os referidos sujeitos políticos se subjetivam como candidatos à presidência, como esse lugar se configura em suas respectivas campanhas. Para tanto, selecionamos para análise trechos dos planos de governo e publicações desses presidenciáveis feitas nas redes sociais Twitter e Facebook durante o período de campanha eleitoral. Após a seleção e a catalogação dos dados, realizamos a análise discursiva das materialidades, com base nos pressupostos teóricos da Escola Francesa de Análise de Discurso, principalmente, nas noções de posição-sujeito e de porta-voz. Os resultados indicam que, no acontecimento discursivo das eleições presidenciais de 2018, a figura enunciativa do porta-voz, identificada na campanha eleitoral dos três candidatos, apesar de falar em nome de uma coletividade, não representa a vontade de um povo brasileiro uno e indiviso, pois a forma de tais candidatos se identificarem com o lugar discursivo do porta-voz aponta para a deriva de sentidos, indicando que essa suposta unidade do "povo brasileiro" é apenas um efeito relacionado à ilusão subjetiva.
\end{abstract}

PALAVRAS-CHAVE: Política; Porta-voz; Posição-sujeito; Religião.

\section{Considerações iniciais}

O ano de 2018 foi marcado, no Brasil, pela realização da primeira eleição presidencial após o impeachment de Dilma Rousseff (PT). Durante o período de campanha eleitoral dos candidatos à presidência da República, circularam nos meios de comunicação e, principalmente, nas mídias sociais, diversas materialidades significantes referentes às candidaturas dos presidenciáveis. Tais materialidades indicam que questões religiosas estiveram

\footnotetext{
* Mestranda em Linguística pela Universidade Estadual do Sudoeste da Bahia (Uesb). Participante do Grupo de Pesquisa em Análise de Discurso (GPADis/UESB), onde desenvolve pesquisa no âmbito do projeto temático Sentidos, sujeitos e religiões na relação com diferentes campos discursivos.

** Doutora em Linguística pela Universidade Estadual de Campinas (Unicamp), instituição em que também realizou estágio pós-doutoral. Professora Titular da Universidade Estadual do Sudoeste da Bahia (Uesb), onde leciona na Graduação em Letras, no Programa de Pós-Graduação em Memória: Linguagem e Sociedade e no Programa de Pós-Graduação em Linguística.
} 
presentes no campo político, seja de forma direta, ao fazer referência a Deus ou ao cristianismo, ou de forma mais indireta, ao suscitar temas que atravessam o campo religioso, como ética, moral, família, ideologia de gênero e aborto. Além disso, consideramos que essas materialidades linguísticas, ao mesmo tempo em que instauram o efeito de novidade, atualizam uma memória que vincula a campanha eleitoral de 2018 a uma rede de acontecimentos que a antecede, tais como escândalos de corrupção, eleições anteriores, antipetismo e polarização partidária.

Considerando essas questões, neste artigo, partimos de dois pressupostos: i) o de que a relação entre discurso político e discurso religioso encontra-se materializada na referida campanha eleitoral ${ }^{1}$; ii) o de que essa campanha se constitui como um acontecimento discursivo $^{2}$, para investigar como funcionam as diferentes posições-sujeito ocupadas pelos candidatos Jair Bolsonaro (PSL), José Maria Eymael (DC) e Cabo Daciolo (Patriota), identificando quais memórias tais posições retomam. Como hipótese, defendemos que funciona, nesse caso, o lugar discursivo do porta-voz e, por isso, buscamos identificar, a partir

1 Esse pressuposto está baseado na tese da precedência do interdiscurso sobre o discurso, que ganhou força na terceira fase da Análise de Discurso, quando, segundo Pêcheux (2014[1983b]), "o primado teórico do outro sobre o mesmo se acentua, empurrando até o limite a crise de maquinaria discursiva estrutural" (PÊCHEUX, (2014[1983b], p. 311). Trata-se de reconhecer a heterogeneidade discursiva, isto é, de considerar o discurso na relação com outros discursos que o antecedem, mas que também o constituem. Tais discursos, segundo Orlandi (2015 [1990]), emergem como uma memória discursiva, definida pela autora como um "saber discursivo que torna possível todo dizer e que retorna sob a forma do pré-construído, o já dito que está na base do dizível, sustentando cada tomada da palavra" (ORLANDI, 2015 [1990], p. 29). Nesse sentido, consideramos que diferentes campos estão em relação interdiscursiva, inclusive os campos religioso e político, uma vez que, conforme pesquisas realizadas sobre as eleições no Brasil, essa relação já está, de alguma forma, vinculada à memória da política brasileira. Como exemplo, citamos a pesquisa de Lessa (2014), que identificou o entrecruzamento do discurso político com o discurso religioso, funcionando a partir da atualização de determinadas memórias, na campanha eleitoral das eleições presidenciais brasileiras de 2010.

${ }^{2}$ Michel Pêcheux (2008 [1983a]) define acontecimento discursivo como o ponto de encontro de uma atualidade e uma memória. A partir da análise do enunciado on a gagné [“Ganhamos”], tal como este atravessou a França no dia 10 de maio de 1981, por ocasião da vitória de Francois Mitterand nas eleições presidenciais. Pêcheux (2008 [1983a] defende que tal enunciado não funciona como proposição estabilizada que designa um acontecimento como um ponto em um espaço de disjunções lógicas. É preciso, segundo o autor, considerar o equívoco da formulação, ou seja, o que é, ao mesmo tempo, da ordem da estrutura e do acontecimento, que corresponde ao novo, à ruptura, ao irremediavelmente equívoco. Consideramos, portanto, neste trabalho, que há um encontro entre memória e atualidade nas formulações que compõem o material de campanha dos candidatos, as quais indicam que, para além do acontecimento histórico, as eleições de 2018 se constituem como um acontecimento discursivo, pois, como afirma Indursky (2003) acerca do referido conceito, nas citadas eleições, há um trabalho de "ruptura do mesmo, com a instauração do novo" (INDURSKY, 2003, p. 108). 
das posições por meio das quais os referidos sujeitos políticos se subjetivam como candidatos à presidência, como esse lugar se configura em suas respectivas campanhas.

Para tanto, analisamos excertos coletados nos planos de governo dos referidos candidatos e também postagens desses presidenciáveis, feitas em suas redes sociais (Twitter e Facebook), durante o período de campanha eleitoral. Nas análises, consideramos os pressupostos teóricos da Escola Francesa de Análise de Discurso, especialmente a noção de posição-sujeito, de Michel Pêcheux (2014 [1975]; 2014 [1978]), e de porta-voz, postulada por Pêcheux (1990 [1982]) e desenvolvida por Zoppi-Fontana (1997). A seguir, apresentamos algumas considerações teóricas acerca desses conceitos operacionais, para, posteriormente, apresentarmos os resultados das análises.

\section{Discurso, sujeito e posição-sujeito}

$\mathrm{Na}$ Análise de Discurso (AD), a língua é considerada base material para processos discursivos e a noção de sujeito não está relacionada ao sujeito empírico, ao indivíduo, mas a um lugar na estrutura social. Para formular a teoria materialista dos processos discursivos, Pêcheux (2014 [1975]) se apropria da tese de Althusser, apresentada em Aparelhos Ideológicos de Estado, segundo a qual a ideologia interpela os individuos em sujeitos. Assim, para chegar à concepção de sujeito do discurso, o autor considera a relação entre ideologia e inconsciente, defendendo que o caráter comum dessas duas categorias "é o de dissimular sua própria existência no interior mesmo do seu funcionamento, produzindo um tecido de evidências 'subjetivas"' (PÊCHEUX (2014 [1975], p. 139, grifos do autor), nas quais o sujeito se constitui. Para o autor, essa evidência espontânea do sujeito aproxima-se da evidência do sentido, de modo que a constituição do sujeito está relacionada à constituição do sentido, no interior da tese central althusseriana, por meio da figura da interpelação.

No processo de construção da teoria, Pêcheux (2014 [1975]) defende a tese segundo a qual a Ideologia interpela os indivíduos em sujeito significa que o "não-sujeito" é constituído em sujeito pela ideologia e, portanto, todo indivíduo é sempre “já-sujeito”. O autor postula ainda que a marca do inconsciente como "discurso do Outro" implica a presença eficaz do "Sujeito" no sujeito, fazendo com que todo sujeito tome posição em "total liberdade" e em 
“total consciência”. Essa tomada de posição, segundo o autor, não diz respeito a um ato originário do sujeito falante, mas ao efeito da determinação do interdiscurso como discurso-transverso, na forma sujeito. Na perspectiva de Pêcheux (2014 [1975]), o sujeito é constituído como autor e responsável pelos seus atos na prática discursiva em que se inscreve, pela determinação da formação ideológica, na qual ele é interpelado a ser "sujeitoresponsável". Essa interpelação, segundo o autor, supõe um desdobramento em sujeito da enunciação (sujeito do discurso) e sujeito universal (o sujeito da ciência ou que se pretende como tal). Tal desdobramento, ainda segundo Pêcheux (2014 [1975]), corresponde à relação entre pré-construído e articulação, e pode assumir diferentes modalidades.

A primeira modalidade caracteriza o discurso do "bom sujeito" e "consiste em uma superposição (um recobrimento) entre o sujeito da enunciação e o sujeito universal, de modo que a 'tomada de posição' do sujeito realiza seu assujeitamento sob a forma do 'livremente consentido" (PÊCHEUX (2014 [1975], p. 199, grifos do autor). Trata-se, portanto, de uma identificação plena do sujeito à formação discursiva. A segunda modalidade caracteriza o discurso do "mau sujeito", que se volta contra o sujeito universal por meio de uma tomada de posição, a qual se configura no distanciamento do sujeito universal. Há, portanto, uma contraidentificação do sujeito do discurso com a formação discursiva que lhe é imposta pelo interdiscurso. Entre essas duas modalidades, segundo o autor, existe um antagonismo (aceitação consentida/recusa), que se manifesta no interior da forma-sujeito na medida em que o efeito do interdiscurso "continua a determinar a identificação ou a contraidentificaşão do sujeito com uma formação discursiva, na qual a evidência do sentido the é fornecida, para que ele se ligue a ela ou que a rejeite" (PÊCHEUX (2014 [1975], p. 200, grifos do autor).

A terceira modalidade diz respeito a uma tomada de posição não subjetiva, "caracterizada pelo fato de que ela integra o efeito das ciências e da prática política do proletariado sobre a forma-sujeito, efeito que toma a forma de uma desidentificação" (PÊCHEUX, 1988[1975], p. 201, grifos do autor). Esse efeito, segundo o autor, se concretiza, paradoxalmente, por meio da apropriação subjetiva dos conceitos científicos e da identificação com as organizações políticas de tipo novo. Assim, nesse funcionamento, há um rompimento do sujeito com a 
formação discursiva em que se inscreveu e, ao mesmo tempo, uma identificação com uma outra formação discursiva e com a sua respectiva forma-sujeito.

A modalidade da desidentificação e a suposição de uma identificação plena são revistas por Pêcheux (2014 [1978]) no texto Só bá causa daquilo que falha ou o inverno político francês: início de uma retificação, o que ele faz com base na teoria lacaniana. Para o autor, a falha do texto Semântica e Discurso: uma crítica à afirmação do óbvio é ter levado muito a sério a ilusão de um ego-sujeito-pleno no qual não há falhas, isto é, a ilusão de uma identificação plena. Segundo Pêcheux (2014 [1978]), não é possível ao sujeito se desidentificar plenamente, pois o que ocorre, no processo de desidentificação, é o deslocamento de uma forma-sujeito para outra com a qual o sujeito se identifica e passa a se inscrever. Porém, nesse deslocamento, não há o apagamento/esquecimento dos saberes da antiga forma-sujeito com os quais o sujeito está se desidentificando, esses são, quando muito, recalcados. Ainda segundo Pêcheux (2014[1978]), é preciso considerar tanto a ideologia quanto o inconsciente no processo de constituição do sujeito.

Segundo Orlandi (2007 [1996]), dizer que ideologia e inconsciente são noções solidárias implica compreender a língua como sistema de ordem significante que se inscreve na história para constituir o sentido, assim como implica considerar o sujeito discursivo enquanto sujeito histórico. Desse modo, ainda conforme a autora, no domínio discursivo, o sujeito é uma posição, dentre outras, e o modo pelo qual ele se constitui, enquanto posição, não lhe é acessível, devido ao efeito da ideologia e à não transparência da linguagem, na qual o sentido não é evidente.

Com base nesses pressupostos teóricos, o sujeito de que tratamos neste artigo não corresponde ao sujeito pragmático, empírico, mas ao sujeito enquanto posição. Então, não nos interessa os sujeitos Cabo Daciolo, José Maria Eymael e Jair Bolsonaro enquanto sujeitos pragmáticos, mas as posições ocupadas por eles nas eleições presidenciais de 2018. Assim, propomos identificar em qual(is) posição(ões) estão subjetivados esses candidatos nas materialidades que foram constituídas durante a campanha eleitoral de 2018.

\section{O lugar discursivo do porta-voz}


Pêcheux (1990 [1982]), no texto Delimitações, inversões, deslocamentos, ao problematizar os efeitos da relação entre língua e história no espaço revolucionário, a partir da análise de três processos históricos, afirma que "a questão histórica das revoluções concerne por diversas vias ao contato entre o visível e o invisível, entre o existente e o alhures, o nãorealizado ou o impossível, entre o presente e as diferentes modalidades da ausência" (PÊCHEUX (1990 [1982]), p. 8). Essa existência do invisível, da ausência, segundo o autor, é materializada na língua, isto é, o encontro entre o real e o imaginário se estabelece por meio da língua.

Na perspectiva de Pêcheux (1990 [1982]), a questão da irrupção do irrealizado, dos efeitos de fronteira e da linguagem pode ser relacionada à figura da interpelação ideológica dos indivíduos em sujeitos, considerando que as práticas ideológicas são reguladas por rituais. Além disso, segundo o autor, "levar até as últimas consequências a interpelação ideológica como ritual supõe o reconhecimento de que não há ritual sem falha, desmaio ou rachadura” (PÊCHEUX (1990 [1982]), p. 17, grifo do autor). Por meio dessa quebra de ritual, conforme o autor, "uma série heterogênea de efeitos individuais entra em ressonância e produz um acontecimento bistórico (PÊCHEUX (1990 [1982]), p. 17, grifo do autor), rompendo, assim, o círculo da repetição. É nesse momento, segundo Pêcheux (1990 [1982]), que surge a posição do porta-voz.

Nas palavras do autor, o porta-voz é, ao mesmo tempo, ator visível e testemunha ocular do acontecimento, de modo que, ao falar em nome de alguém ou de um grupo, exerce "um efeito visual, que determina esta conversão do olhar pela qual o invisível do acontecimento se deixa enfim ser visto: o porta voz se expõe ao olhar do poder que ele afronta, falando em nome daqueles que ele representa, e sob o seu olhar" (PÊCHEUX (1990 [1982]), p. 17). Trata-se, ainda conforme o autor, de uma dupla visibilidade que coloca o porta-voz numa posição de negociador em potencial, em contato imediato com o adversário exterior. Assim, a posição do porta-voz indica a possibilidade do novo, torna o "nós", que ainda não foi realizado, possível de ser visto.

Segundo Pêcheux (1990 [1982]), o destino do porta-voz circula entre as posições de profeta, de dirigente e de homem de Estado, pois “ele é o ponto em que 'o outro mundo' 
se confronta com o estado de coisas existente, o ponto de partida recíproco no qual a contradição vem se amarrar politicamente a um 'negócio de Estado"' (PÊCHEUX (1990 [1982]), p. 18). Ao chamar para si a questão do Estado, conforme o autor, o porta-voz é confrontado aos efeitos recorrentes do trabalho revolucionário da memória, onde estão sedimentados todos os discursos que o precederam.

Considerando os postulados de Conein (1981) e de Pêcheux (1982), Zoppi-Fontana (1997) afirma que a figura do porta-voz é definida como um funcionamento enunciativo de mediação da linguagem, sendo que tal função enunciativa "se configura como uma relação de destinação da palavra realizada em duas direções: do grupo para o porta-voz e através deste para o poder ou adversário, e do poder ou adversário para o grupo" (ZOPPIFONTANA, 1997, p. 20). Desse modo, segundo a autora, passam necessariamente pelo porta-voz direções que se representam no discurso político contemporâneo como "povo"líder e líder -"povo".

Na perspectiva de Zoppi-Fontana (1997), a contradição constitutiva da figura do porta-voz (ator visível e testemunha ocular do acontecimento) o coloca como ponto de encontro de funcionamentos opostos: de um lado, os processos discursivos de identificação, que unem o porta-voz aos representados, sob a ilusão do mesmo; e, de outro lado, os processos discursivos de diferenciação, que o diferenciam do grupo que representa. Para a autora, a figura do porta-voz configura-se, no nível do imaginário, como lugar de enunciação coletiva, onde "povo" e "líder" são constituídos com base em uma ilusão de interlocução, a partir da qual se define um pacto dialógico entre as imagens de locutor (porta-voz; o "nós", o "igual" que se destaca do grupo) e de alocutário (um todo uniforme; imagem de "povo uno") 3 .

Zoppi-Fontana (1997) afirma que, por pressupor a presença do interdiscurso na enunciação, é possível tornar visível a contradição constitutiva do porta-voz e os

\footnotetext{
${ }^{3}$ Zoppi-Fontana (1997) utiliza a noção de imagens do locutor e do alocutário no sentido de Pêcheux (1969), como representações imaginárias constituídas a partir de processos discursivos que determinam as posições de sujeito de um discurso.
} 
deslocamentos das diferentes posições-sujeito que essa contradição provoca. Nesse sentido, a autora explica que, apesar de manter a terminologia de Pêcheux ao descrever a "dupla visibilidade" do porta-voz, ela entende a representação de testemunha/espectador do acontecimento discursivo, constitutiva do porta voz, "como efeito da inscrição ideológica do sujeito do discurso numa determinada posição de sujeito estabelecida no complexo com dominante de FDs, que constituem o interdiscurso" (ZOPPI-FONTANA, 1997, p. 198, grifos da autora).

Assim, para a autora, as posições-sujeito que configuram o sujeito do discurso são estabelecidas em relação às formações discursivas e coexistem no interior da figura do porta-voz, determinando o funcionamento dessa forma de constituição do sujeito da enunciação política. Em seguida, buscamos identificar em quais posições-sujeito se subjetivaram três candidatos à presidência da República e de que maneira buscam se constituir como porta-vozes.

\section{Posição-sujeito e porta-voz na campanha eleitoral dos candidatos José Maria Ey- mael (DC), Cabo Daciolo (Patriota) e Jair Bolsonaro (PSL)}

A campanha eleitoral oficial das eleições de 2018 ocorreu no período de 16 de agosto a 27 de outubro e seguiu as novas regras eleitorais, segundo a reforma política aprovada em outubro de 2017. Dentre essas regras, podemos citar a redução do tempo de campanha, que passou de 90 para 45 dias, em relação às eleições de 2014, e o estabelecimento de um teto de gastos para as campanhas. Além disso, a Justiça Eleitoral regulamentou a campanha eleitoral nas redes sociais, permitindo aos candidatos pagarem para impulsionar conteúdos nessas redes e receberem doações por meio de "vaquinhas virtuais".

Diante dessas mudanças no cenário eleitoral, os candidatos utilizaram a internet e, principalmente, as redes sociais Facebook e Twitter, além do Whatsapp, como ferramentas de campanha. A seguir, apresentamos uma análise discursiva de excertos extraídos dos Planos 
de Governo e das publicações em redes sociais oficiais dos candidatos à presidência da República José Maria Eymael (DC), Cabo Daciolo (Patriota) e Jair Bolsonaro (PSL)4.

Considerando o discurso como efeito-sentido entre interlocutores, que são entendidos como lugares na estrutura social, verificamos quais posições-sujeitos estão materializadas nos excertos selecionados e (se/como) funciona o lugar discursivo do porta-voz no material de campanha desses candidatos. Os primeiros excertos analisados foram coletados no plano de governo do candidato José Maria Eymael (DC). Vejamos:

\section{Excerto 1: COMPROMISSO COM A FAMÍLIA}

O resgate e a proteção dos valores éticos da Família e a satisfação plena de suas necessidades serão o fundamento, a inspiração e o objetivo permanente da Democracia Cristã, no exercício da Presidência da República (Plano de Governo, p. 01).

Excerto 2: Governar o País com ética, segundo os princípios da Democracia Cristã, COMBATENDO TODAS AS FORMAS DE CORRUPÇÃO (Plano de Governo, p. 07).

Os excertos acima apresentam metas do plano de governo do candidato. Nessas materialidades linguísticas, o presidenciável ocupa a posição-sujeito político-partidária, tendo em vista que propõe um novo Brasil a partir dos princípios defendidos pelo partido Democracia Cristã. Observamos, ainda, nos excertos 1 e 2, o atravessamento do discurso religioso, uma vez que os princípios do referido partido estão fundamentados na dignidade da pessoa humana e nos valores humanísticos do Cristianismo ${ }^{5}$. Desse modo, "o resgate e a proteção dos valores éticos da Família e a satisfação plena de suas necessidades" assim como "Governar o País com ética" são compromissos políticos que têm como base os ensinamentos e os princípios cristãos. A expressão "o resgate e a proteção dos valores éticos da Família" indica um pré-construído segundo o qual a família brasileira perdeu os

\footnotetext{
${ }^{4}$ As análises preliminares dos materiais de campanha de todos os presidenciáveis, para a constituição do corpus de pesquisa, indicaram que a referência ao campo religioso aparecia de forma mais acentuada nas campanhas desses três candidatos, seja nos slogans ou nas propostas. Por esse motivo, as campanhas eleitorais desses candidatos foram selecionadas para análise.

${ }^{5}$ Informação obtida em: https://cutt.ly/pf2exZK. Acesso em: 06/09/2020.
} 
seus valores éticos, os quais precisam ser resgatados. E isso só poderá ser feito por um governante que considera a família como base fundamental da sociedade, segundo os princípios cristãos. Analisamos, a seguir, publicações do candidato José Maria Eymael (DC) feitas na rede social Facebook.

Excerto 3: Cumpri meu dever cívico de cidadão: escolher aqueles que irão dirigir os destinos desta nação pelos próximos 4 anos. Votar é Escolher! Votar é encontrar Caminhos! Votar é Cidadania! Competência, Honra e Caráter! Que Deus abençoe nossa Nação e nosso povo, na missão de Construir uma Sociedade Livre, Justa e Solidária, como escrevi na Constituição do Brasil! (Facebook, 01/10/2018, grifo nosso).

Excerto 4: Quero saudar a vinda, e são tantos, de apoiadores de outras Candidaturas a Presidente, e que agora se juntam à força magnífica e vencedora da Democracia Cristã - DC. E juntos, entoamos o Jingle que embala o sonho de um povo, por um novo e melhor Brasil : Ey, Ey, Eymael, um Democrata Cristão! Sinais! Fortes Sinais! (Facebook, 30/09/2018, grifo nosso).

Nessa série de excertos, identificamos o funcionamento da posição-sujeito portavoz representante do povo. Considerando os postulados de Pêcheux (1990 [1982]), a figura do porta-voz é o ponto de confronto entre "o outro mundo possível" e o estado de coisas existente. Esse funcionamento pode ser visto no excerto 3, na medida em que o sujeito político é apresentado como aquele que tem a "missão de Construir uma Sociedade Livre, Justa e Solidária". Trata-se, portanto, da representação do sujeito político como o agente da mudança do país, aquele que tem uma missão de instituir o novo, o que se confronta com a situação atual do país, conforme indicado também no referido excerto. Isso está marcado na língua pelo uso do verbo "construir", pois este, além de indicar algo novo, traz um pré-construído de que o Brasil não é uma sociedade livre, justa e solidária.

Esse funcionamento da figura do porta-voz como agente da mudança também pode ser visto no excerto 4, pois o sujeito político indica a possibilidade de um outro mundo, "um novo e melhor Brasil". Além disso, observamos, conforme Zoppi-Fontana (1997), uma ilusória relação de interlocução, "em que a voz (o poder político e a demanda) circula simetricamente como efeito de um processo duplo de delegação: o líder como porta-voz 
do povo e, reciprocamente, o povo como porta-voz (herdeiro) do seu líder" (ZOPPIFONTANA, 1997, p. 61). Desse modo, o sujeito político, que aqui se pretende porta-voz, propõe-se a ocupar o lugar de presidente da República para realizar "o sonho de um povo". Esse povo que ele representa é constituído imaginariamente como uno, uniforme, e que tem o mesmo desejo: o de ter José Maria Eymael, um democrata cristão, governando o país. A seguir, analisamos excertos do plano de governo e de publicações feitas na rede social Facebook do candidato Cabo Daciolo (Patriota).

Excerto 5: Tenho a honra de apresentar as linhas gerais da nossa proposta de governo, como candidato à Presidência da República pelo PATRIOTA. Essa é uma batalha que não é só minha, mas de todos os BRASILEIROS que acreditam que podemos reconstruir o Brasil em bases que honrem a Deus e tragam dignidade ao povo (Plano de Governo, p. 02, grifo nosso).

Excerto 6: Convém que se diga também que o próprio Bolsonaro frequenta lojas maçônicas, o que já o desqualifica para essa batalha que se dá no campo espiritual. Nossa luta é contra as potestades do mal. Lembrem-se: estamos lutando uma guerra no mundo espiritual. É aí que Deus nos dará vitória (Facebook, 12/09/18, grifo nosso).

Excerto 7: DEUS NOS LEVANTOU PARA PROTEGERMOS A NOSSA NAÇÃO! GLÓRIA A DEUS! JUNTOS SOMOS FORTES

NEM UM PASSO DAREMOS ATRÁS.

DEUS ESTÁ NO CONTROLE (Facebook, 01/10/18, grifo nosso).

Excerto 8: O CAMINHO, A VERDADE E A VIDA!

A solução para a NAÇÃO BRASILEIRA não passa pela política ou pelas mãos aqueles que nunca fizeram NADA por este país. A solução está em JESUS CRISTO, Rei dos reis, autor e consumador da nossa fé. Sou apenas um instrumento nas mãos de Deus e tenho certeza de que posso, por meio de Cristo, fazer grandes coisas pela NAÇÃO BRASILEIRA (Facebook, 18/08/18, grifo nosso).

Nos excertos acima, o candidato Cabo Daciolo assume as posições-sujeito político e religioso. Nas formulações 5 e 6 , observamos o atravessamento do discurso religioso no campo político a partir da vinculação de elementos ligados à religião ao processo eleitoral, 
por meio da nomeação das eleições como "batalha", "luta", "guerra", léxico que se aproxima daquele usado pelas religiões, principalmente as cristãs, quando se referem a relação entre mundo carnal e mundo espiritual. Assim, por um efeito metafórico em que a disputa eleitoral é substituída por expressões vinculadas ao campo religioso, ocorre um deslizamento de sentidos do modo de significar as eleições presidenciais de 2018.

Também está em funcionamento, nos excertos 5, 6 e 7, a figura enunciativa do porta-voz, tendo em vista que o sujeito político Cabo Daciolo, a partir da posição-sujeito que ocupa, fala em nome de um grupo do qual se destaca como "centro visível de um 'nós' em formação e também em contato imediato com o adversário exterior" (PÊCHEUX, (1990 [1982], p. 17). No caso em questão, esse “nós" seria “todos os BRASILEIROS que acreditam que podemos reconstruir o Brasil em bases que honrem a Deus e tragam dignidade ao povo", conforme apresentado no excerto 5. Trata-se daqueles brasileiros que se identificam com a posição-sujeito religioso que o candidato ocupa. Do mesmo modo, esses "nós" está marcado linguisticamente pelas expressões "Nossa luta" (6), "Deus nos levantou para protegermos a nossa Nação [...] Juntos somos mais fortes. Nenhum passo daremos atrás" (7), que apontam para o porta-voz falando em nome de uma coletividade, a qual deseja que o país seja governado por um cristão.

Nessa série de formulações ( 5 a 8 ), a proposta de um novo mundo possível apresentada pelo sujeito político Cabo Daciolo é feita com base em princípios cristãos, pois, conforme os excertos citados, essa mudança se daria a partir do mundo espiritual, uma vez que Deus seria o agente de todas as ações do referido sujeito político enquanto presidente da República. Nesse sentido, o funcionamento da figura do porta-voz se dá, também, a partir da identificação do sujeito político Daciolo com a posição-sujeito mensageiro de Deus, visto que, ao se enunciar como o escolhido (7) e como instrumento de Deus (8), ele legitima sua prática política pelo discurso religioso, exercendo, portanto, a função enunciativa de mediador do querer divino. Assim, o voto no candidato Cabo Daciolo significaria, de acordo com o discurso materializado nos excertos acima analisados, a manifestação da vontade de Deus, a qual é, ainda segundo o discurso materializado nos excertos, o único 
meio para se alcançar esse novo mundo. Analisamos, a seguir, duas publicações do referido candidato feitas na sua página do Facebook.

Excerto 9: Empresas estatais estratégicas jamais serão privatizadas em nosso governo. (...) Iremos fortalecer a soberania brasileira em todos os setores, pois o país perdeu muito de sua autonomia para tomar decisões devido aos grandes interesses estrangeiros que permearam as decisões políticas (Plano de Governo, p. 15, grifo nosso).

Excerto 10: Precisamos fortalecer os pilares da Seguridade Social, combater a corrupção e aplicar de forma honesta e inteligente o dinheiro arrecadado. CHEGA DE DESVIOS E ROUBALHEIRA! CABO DACIOLO 51JUNTOS SOMOS FORTES NEM UM PASSO DAREMOS ATRÁS DEUS ESTÁ NO CONTROLE (Facebook, 30/08/18, grifo nosso).

Nessa série de excertos, observamos a posição do porta-voz em funcionamento, visto que o sujeito político se constitui, ao mesmo tempo, como ator visível (participa das ações do grupo que representa) e testemunha ocular do acontecimento (diferencia-se do grupo, ocupando lugar de destaque), conforme destaca Pêcheux (1990 [1982], p. 17). Essa dupla visibilidade, constitutiva do porta-voz, possibilita que o sujeito político Daciolo, ao apresentar suas propostas, fale em nome daqueles que representa, ao mesmo tempo que está sob o olhar do adversário. Trata-se, segundo Zoppi-Fontana (1997), de uma “dupla direção da função enunciativa que define o porta-voz como aquele a quem se dá e de quem se cobra a vOz" (ZOPPI-FONTANA, 1997, p. 88). Esse funcionamento está materializado linguisticamente nos excertos em análise pelo "nós” elíptico dos verbos "iremos", "somos", "precisamos" e pelo pronome possessivo "nosso", pois ambos os pronomes ("nós" e "nosso") marcam o compromisso assumido pelo sujeito político com o seu "povo", o qual ele representa e por quem poderá ser cobrado.

$\mathrm{Na}$ apresentação das propostas, transcritas nos excertos 9 e 10, o sujeito político figura como profeta ao vislumbrar "o outro mundo", um novo Brasil, mas, ao mesmo tempo, atualiza certa memória referente à política brasileira. Assim, no excerto 9, o candidato retoma a memória das privatizações de empresas estatais já ocorridas no Brasil, para afirmar o caráter patriota do seu governo, ao propor o fortalecimento da soberania 
brasileira, ocupando, portanto, uma posição-sujeito nacionalista. No excerto 10, é retomada a memória dos escândalos de corrupção ocorridos nos governos anteriores, para marcar o posicionamento do candidato como o político honesto, aquele que vai "combater a corrupção". Além disso, a formulação "Deus está no controle" indica que o candidato se subjetiva na posição de mediador da vontade divina, tendo em vista que as suas ações são controladas por Deus. Os próximos excertos que serão analisados são publicações do candidato Jair Bolsonaro feitas na rede social Twitter.

Excerto 11: Agradeço aos movimentos espontâneos espalhados por todo o Brasil neste final de semana por minha recuperação. Tenham certeza que isso nos dá forças para cumprir nossa missão! Vamos mudar o Brasil! Muito obrigado a todos! (Twitter, 16/09/18, grifo nosso).

Excerto 12: O que incomoda muitos é que o apoio que recebemos é espontâneo, algo que nunca tiveram. Não é por Bolsonaro, mas pelo Brasil, que foi saqueado e jogado às traças. São todas as cores, idades, sexo e classe social, confiantes na chegada de um futuro melhor. Isso é imbatível! (Twitter, 26/09/18, grifo nosso).

Excerto 13: Estamos iniciando a última semana a caminho de, se Deus quiser, nossa nova Independência! Vamos tirar o Brasil do vermelho e devolvê-lo aos brasileiros! (Twitter, 22/10/18, grifo nosso).

No excerto 11, o substantivo "missão" foi utilizado para fazer referência à possível mudança do Brasil em virtude da suposta vitória do candidato Jair Bolsonaro na disputa pelo cargo de presidente da República. Desse modo, o uso da palavra "missão", no excerto citado, produz o efeito-sentido de que mudar o Brasil é uma incumbência, uma tarefa destinada ao candidato Jair Bolsonaro. Nesse caso, o referido candidato assume a posiçãosujeito de missionário, isto é, aquele que foi designado para promover a transformação do Brasil, o que implica, dentre outras questões, conforme o excerto 13, "tirar o Brasil do vermelho e devolvê-lo aos brasileiros". Esta última formulação, por um efeito de memória sobre a atualidade, produz um duplo efeito-sentido, pois "tirar o Brasil do vermelho" significa tanto ajustar as contas públicas do país quanto impossibilitar o PT e/ou outros partidos da esquerda, que usam a cor vermelha em suas bandeiras, de assumir o poder. Essa 
associação pode ser feita devido às críticas contra o PT (grafadas, na maioria dos casos, na cor vermelha) presentes no plano de governo do candidato, assim como pela atualização da memória de uma campanha publicitária em defesa do ajuste fiscal (PEC do congelamento de gastos), que circulou na mídia impressa em 2016, no governo de Michel Temer,

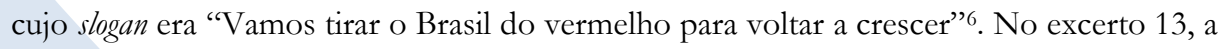
formulação "se Deus quiser" indica que a concretização da missão de "tirar o Brasil do vermelho" está condicionada ao querer divino, o que associa o candidato Jair Bolsonaro a uma posição-sujeito de mediador da vontade de Deus, aquele que fará o que Deus quer para o Brasil.

Ainda em relação ao funcionamento da figura enunciativa do porta-voz, vemos que o sujeito político Jair Bolsonaro não fala por si, mas em nome de uma coletividade. Isso pode ser identificado pelo uso dos pronomes possessivos "nossa" (11 e 13) "nosso" (11), assim como pelo uso dos verbos "estamos" (13), "recebemos" (12) e "vamos" (13), que mostram o candidato falando em nome de um "nós", o qual funciona como lugar discursivo de coletividade. Do mesmo modo, na expressão "Não é por Bolsonaro, mas pelo Brasil" (12), o efeito-sentido é de que o candidato fala em nome de toda a sociedade brasileira, como se fosse desejo de todo o país que ele se tornasse presidente, ou seja, produz um efeito ilusório de universalidade quando fala "pelo Brasil". As formulações seguintes apresentam compromissos assumidos pelo candidato em nome dessa coletividade que suspostamente representa. Vejamos:

Excerto 14: Faremos um Governo que confiará no cidadão, simplificando e quebrando a lógica que a esquerda nos impôs de desconfiar das pessoas corretas e trabalhadoras (...) O GOVERNO

\footnotetext{
${ }^{6}$ A campanha cujo título era "Vamos tirar o Brasil do vermelho para voltar a crescer" e subtítulo "O Governo Federal encontrou uma situação muito grave nas contas públicas” elencava uma série de dados referentes às contas públicas do Brasil. Após ser veiculada em anúncios de jornais impressos, foi alvo de questionamentos pela bancada do PT, no Senado, que cobrou explicações ao então ministro-chefe da Casa Civil, Eliseu Padilha, alegando que a referida campanha se tratava de violação aos princípios constitucionais de impessoalidade e moralidade, por ter um caráter político-partidário. O slogan não chegou a ser veiculado nos vídeos da campanha e foi substituído por "Equilibrar as contas públicas, isso é governar com responsabilidade". Informação obtida em: https://cutt.ly/Yf2rv6S e https://cutt.ly/Sf2rnbL. Acesso em 10/09/2020.
} 
VAI CONFIAR NOS INDIVIDUOS! O GOVERNO RECUARÁ, PARA QUE OS CIDADÃOS POSSAM AVANÇAR! (Plano de Governo, p. 20, grifo nosso).

Excerto 15: Para combater o desemprego o Brasil precisa de confiança e segurança. Investidores não confiam no Brasil, milhares de empresas fecharam devido a violência, altos impostos, burocracia, corrupção e crise, tudo herança do PT. Nós mudaremos esse quadro. Seremos o governo do emprego! (Twitter, 25/10/18, grifo nosso).

Excerto 16: Está chegando o momento da mudança; de nosso valor ser medido pelo nosso caráter, não pela nossa cor, sexo ou crença; de governar pelo exemplo; de se espelhar em grandes nações; de se livrar das amarras ideológicas; de por fim ao sistema falido que impera há décadas no Brasil! (Twitter, 02/10/18, grifo nosso).

Nessas formulações, o sujeito político Jair Bolsonaro, ao assumir compromissos "pelo povo" e "para o povo", apresenta as características que seriam do novo Brasil, proposto pela sua candidatura. Desse modo, ele indica que está subjetivado na posição-sujeito agente da mudança (porta-voz), entretanto, considerando os postulados de Pêcheux (1990 [1982]), segundo os quais todo processo revolucionário ${ }^{7}$ tem em si algo do processo anterior, identificamos nos excertos apresentados a proposta de um novo Brasil a partir do retorno de uma memória referente ao governo do PT. Nas formulações, o agente da mudança ocupa o lugar de fronteira entre o que seria o Brasil governando pela esquerda e a forma de governar proposta pelo candidato. Desse modo, a emergência da mudança, nos excertos, se dá, não pela construção de um novo programa de governo, mas pela desmontagem do sistema político que teria sido instituído nos anos em que o PT governou o Brasil, como se verifica na expressão "tudo herança do PT" (15). Essa proposta de um novo Brasil

\footnotetext{
7 Pêcheux (1990 [1982]) trata, em seu texto, como indicado acima, de processos revolucionários, nos quais o porta-voz é constituído como o agente da mudança. Mas, é possível fazer um deslocamento e pensar na noção de porta-voz para além de processos revolucionários strictu sensu, como, por exemplo, faz Zoppi-Fontana (1997), que se apropria da noção de porta-voz para pensar o contexto eleitoral argentino. Nesse sentido, quando retomamos a noção de porta-voz, nas análises aqui apresentadas, não estamos comparando as eleições de 2018, no Brasil (e muito menos a vitória de Jair Messias Bolsonaro), a um processo revolucionário, mas, reconfiguramos, a exemplo de Zoppi-Fontana (1997), a noção de porta-voz para fazê-lo funcionar em relação a qualquer processo de mudança, principalmente na esfera política.
} 
(sem corrupção, violência, desemprego, altos impostos, crise), a partir da dissolução do que estaria posto na sociedade, pode ser identificada nas formulações "quebrando a lógica que a esquerda nos impôs" (14); "se livrar das amarras ideológicas" (16) e "por fim ao sistema falido que impera há décadas no Brasil" (16), cujos verbos produzem o efeito-sentido de desconstrução. A proposta de um novo país também está presente nos excertos 17 a 19, transcritos abaixo, nos quais a mudança está condicionada à extinção da corrupção no país. Vejamos:

Excerto 17: Se for da vontade de Deus, amanhã será o dia de nossa nova independência. Vamos derrotar o partido dos maiores escândalos de corrupção da história, do Petrolão, do Mensalão, do Foro de SP, dos inimigos da liberdade e da Constituição! Devolveremos o Brasil aos brasileiros de bem! (Twitter, 27/10/18, grifo nosso).

Excerto 18: Mais importante: uma Nação fraterna e humana, com menos excluídos, é mais forte. Há menos espaço para populistas e suas mentiras. O Brasil precisa se libertar dos corruptos. $O$ povo brasileiro precisa ser livre de VERDADE! (Plano de governo, p. 06, grifo nosso).

Excerto 19: Represento uma ameaça sim, aos corruptos, à bandidagem, aos estupradores, aos esquemas que assaltam o BNDES, aos assassinos e aos que querem destruir o Brasil! Por isso estão desesperados! NÃO TERÃO SOSSEGO EM MEU GOVERNO! (Twitter, 26/10/18, grifo nosso).

Nessa série de excertos, identificamos a atualização de uma memória sobre a corrupção, produzindo efeitos de sentido sobre a política brasileira, sobre o PT e sobre a possível vitória do candidato Jair Bolsonaro. A relação interparafrástica das formulações apresentadas acima indica o funcionamento de um discurso segundo o qual o Brasil está dominado e destruído pela corrupção, da qual precisa se libertar, conforme se verifica nas orações "O Brasil precisa se libertar dos corruptos" (18) e "O povo brasileiro precisa ser livre de VERDADE!" (18), cuja locução adverbial “de verdade”, escrita em caixa alta, materializa o pré-construído de que existe uma falsa liberdade no Brasil, tendo em vista que, segundo o excerto, o país está preso à corrupção. Considerando a relação entre os excertos e uma atualização da memória dos escândalos de corrupção ocorridos durante o governo do 
PT (Mensalão e Petrolão), mencionados no excerto 17, podemos dizer que, nas formulações, a corrupção está associada ao PT, nomeado no excerto 17 como "o partido dos maiores escândalos de corrupção da história", o que produz o efeito-sentido de que livrar o Brasil da corrupção significaria livrar o Brasil do PT e vice-versa. Desse modo, essas formulações atualizam uma memória sobre o PT enquanto partido corrupto, criminoso, destruidor do país, mentiroso, populista, inimigo da "liberdade e da Constituição" e que, por tudo isso, precisa ser derrotado, expurgado da política brasileira.

Nas formulações "Vamos derrotar o partido dos maiores escândalos de corrupção da história" (17), e "Represento uma ameaça sim, aos corruptos, à bandidagem, aos estupradores, aos esquemas que assaltam o BNDES, aos assassinos e aos que querem destruir o Brasil!” (19), o candidato Jair Bolsonaro ocupa a posição-sujeito político honesto, anticorrupção, aquele que tem os requisitos necessários para libertar o Brasil do PT e, consequentemente, acabar com a violência, a impunidade e a corrupção no país. Além disso, ocupa a posição-sujeito religioso, tendo em vista que, no excerto 17, afirma que ele ganhar as eleições está condicionado ao querer divino, conforme se verifica na formulação "se for da vontade de Deus, amanhã será o dia de nossa nova independência”. De modo geral, o efeito-sentido produzido no jogo dessas formulações é de que a vitória do candidato Jair Bolsonaro nas eleições de 2018 significa o fim do PT, da corrupção política, é a salvação do Brasil e a materialização da vontade de Deus. Os excertos seguintes apresentam outras pautas defendidas por Jair Bolsonaro durante a sua campanha, as quais marcam a identificação do candidato com outras posições-sujeito. Vejamos:

Excerto 20: Momento de resgatar nosso orgulho de ser brasileiro; de estampar nossa bandeira verde e amarela em nossas casas; de resgatarmos nosso direito de ir e vir; Falta pouco para darmos o primeiro passo em direção à grandeza! Brasil acima de tudo, Deus acima de todos! (Twitter, 02/10/18, grifo nosso).

Excerto 21: Depois de décadas, o Brasil finalmente tem a chance de eleger um presidente que carrega verdadeiramente os valores dos Brasileiros. Vamos juntos mudar os rumos da nossa nação! Vamos votar Jair Bolsonaro presidente 17 ! Um forte abraço a todos e até a vitória, se Deus quiser! (Twitter, 27/10/18, grifo nosso). 
Excerto 22: O PT agora tenta jogar católicos e evangélicos uns contra os outros. Essa divisão ofende várias famílias que, assim como a minha, são formadas por diferentes vertentes. Não conseguirão! Estamos todos unidos contra a inversão de valores que impera há anos e que destrói nosso país! (Twitter, 12/10/18, grifo nosso).

Excerto 23: Não esqueçam! Desde o início somos contra o controle da mídia e da internet. Desde o início defendemos a inocência das crianças nas escolas. Desde o início somos contra o aborto. Desde o início defendemos a prisão de bandidos e não o desencarceramento. Recusem imitações! (Twitter, 17/10/18, grifo nosso).

No excerto 20, a referência ao símbolo da bandeira nacional brasileira, associada ao orgulho de ser brasileiro, marca a posição-sujeito nacionalista/patriota, assim como o slogan de campanha "Brasil acima de tudo, Deus acima de todos! ”. Além de produzir o efeitosentido de patriotismo, esse slogan associa o sujeito político Jair Bolsonaro à posição-sujeito religioso, uma vez que a expressão "Deus acima de todos" produz o efeito-sentido de supremacia divina, atualizando a memória do primeiro mandamento bíblico "Amar a Deus sobre todas as coisas" (Êxodo 20:3). Assim, podemos dizer que o slogan de campanha do referido candidato materializa o atravessamento do discurso religioso no campo político.

Nesses excertos, o sujeito político Jair Bolsonaro ocupa, também, a posição-sujeito conservador/moralista, que se encontra materializada nas formulações "estamos todos unidos contra a inversão de valores que impera há anos e que destrói nosso país!” (22), “somos contra o aborto" (23) e "defendemos a inocência das crianças nas escolas" (23). A última formulação remete à polêmica referente ao Projeto Escola sem Homofobia, que emergiu nas eleições de 2018 por conta das fake news que circularam na sociedade a respeito do suposto "kit gay". As formulações aqui citadas, associadas ao enunciado linguístico 
"Depois de décadas, o Brasil finalmente tem a chance de eleger um presidente que carrega verdadeiramente os valores dos Brasileiros" (21), produzem o efeito-sentido de que a implementação de políticas educacionais referentes a questões de gênero se configura como uma inversão de valores da sociedade, cuja responsabilidade teria sido do PT, tendo em vista que este foi o partido que esteve no poder nos últimos anos no Brasil.

Assim, cria-se o efeito-sentido segundo o qual o governo do PT busca destruir valores tradicionais dos brasileiros, associado a um outro efeito, o de que o candidato Jair Bolsonaro é o único capaz de reverter essa situação, resgatando esses valores, que seriam, conforme os excertos, a defesa dos princípios cristãos, do patriotismo, da vida (oposição ao aborto), da família tradicional, além da rejeição a questões referentes a gênero (oposição à discussão sobre gênero no contexto escolar, por considerar tal discussão uma forma de incentivo a uma sexualização precoce das crianças e também uma anulação das diferenças/aptidões tidas como "naturais" de cada sexo). Em síntese, na série de excertos acima destacada, o sujeito político Bolsonaro fala a partir de um lugar discursivo coletivo que se identifica com posições-sujeito nacionalista, religioso, conservador e moralista. Vejamos, agora, excertos nos quais são apresentadas as propostas do candidato Bolsonaro em relação às políticas contra a violência no Brasil.

Excerto 24: BANDIDO armado até os dentes atirando em homens, mulheres e crianças inocentes só se resolve na bala. Quem não considera este fato ignora a própria realidade que estamos vivendo e esse é um sinal de que tudo permanecerá do mesmo jeito. Nós entendemos e buscaremos a mudança! (Twitter, 30/08/18, grifo nosso).

Excerto 25: Vamos pegar pesado contra a violência para termos um Brasil mais seguro e livre para todas as pessoas, independente de cor, sexualidade e religião. Queremos devolver à população o prazer de andar na rua sem medo, de viver sem medo. Nosso inimigo é o crime, não o cidadão! (Twitter, 09/10/18, grifo nosso).

Jornal Nacional (Rede Globo), o candidato Fernando Haddad de ter distribuído, quando era Ministro da Educação, um material denominado por Bolsonaro de "kit gay". Esta acusação se tornou um dos principais temas das chamadas "fake news" que circularam no período de campanha eleitoral. A falsidade dessa informação foi confirmada pelo Tribunal Superior Eleitoral (TSE), que solicitou a suspensão de links de sites e redes sociais que continham a referida expressão, em 15 de outubro de 2018. Informações obtidas em: https://cutt.ly/Sf2tio3 e https://cutt.ly/Rf2rrK2. Acesso em 12/09/2020. 
Excerto 26: Meu adversário falou que vai combater o encarceramento e soltar criminosos da cadeia. Nossa preocupação e prioridade são as pessoas de bem. Falo desde sempre, prefiro uma cadeia lotada de criminosos do que um cemitério lotado de inocentes. Se faltar espaço, a gente constrói mais! (Twitter, 09/10/18, grifo nosso).

Nesses excertos, há a materialização de um discurso segundo o qual é possível resolver o problema da violência por meio do recrudescimento penal e pelo uso rigoroso de medidas punitivas. Nesse sentido, o uso da expressão popular "pegar pesado" contra a violência, apesar de não apresentar nenhuma proposta concreta, indica a promessa de um governo que agirá com repressão contra a criminalidade. No excerto 26 , há uma defesa do encarceramento em massa como medida punitiva, independentemente das condições a que os presos serão submetidos, conforme se verifica na formulação "prefiro uma cadeia lotada de criminosos do que um cemitério lotado de inocentes. Se faltar espaço, a gente constrói mais!” (26). Desse modo, verificamos que o sujeito político Jair Bolsonaro se identifica com uma posição-sujeito punitivista e, consequentemente, se contraidentifica com uma posiçãosujeito que incentiva políticas de ressocialização e humanitárias em favor dos presos, o que o associa ao funcionamento discursivo da política de extrema-direita, caracterizada, dentre outras questões, pelo autoritarismo?

No excerto 24, a formulação "BANDIDO armado até os dentes atirando em homens, mulheres e crianças inocentes só se resolve na bala" associa o candidato a uma posição-sujeito punitivista extremista, que nega os direitos humanos, tendo em vista que a expressão "só se resolve na bala" produz um efeito-sentido de negação do direito à vida

\footnotetext{
${ }^{9}$ Segundo Lowy (2015), a política atual de extrema-direita, apesar de procurar se distanciar dos regimes fascistas, pela aceitação da democracia parlamentar, ainda apresenta muitas características desses regimes, tais como a defesa de valores e instituições tradicionais, do nacionalismo, do racismo, da xenofobia, da misoginia e de medidas autoritárias contra o que considera insegurança. Nas palavras do autor, por mais que os partidos de extrema-direita tenham ideologias similares, as suas práticas políticas não são homogêneas. No caso do Brasil, segundo ele, diferentemente da Europa, não há partidos de massa, tendo o racismo como bandeira principal, entretanto, assim como a extrema-direita francesa, a brasileira defende um conservadorismo mais reacionário referente a dois temas principais: 1) "a ideologia repressiva, o culto da violência policial, o chamado a restabelecer a pena de morte" (LOWY, 2015, p. 662), representada no Congresso Brasileiro pela "bancada da bala"; 2) a intolerância à diversidade de gênero, agitada no Brasil, principalmente, por setores religiosos com referência neopentecostal.
} 
àquele que infringe a lei. $\mathrm{O}$ excerto 26 estabelece uma diferença ideológica entre a candidatura de Bolsonaro e a do seu adversário, de modo que a proposta de redução do encarceramento em massa, apresentada por Fernando Haddad, é caracterizada pelo candidato Bolsonaro como sinônimo de impunidade e de libertação de criminosos. Esse excerto produz o efeito-sentido de que o candidato Bolsonaro estaria do lado do cidadão, da sociedade, das pessoas de bem, enquanto o seu adversário teria como objetivo proteger o crime. As expressões "Nós entendemos e buscaremos a mudança!” (24) e “Queremos devolver à população o prazer de andar na rua sem medo, de viver sem medo. Nosso inimigo é o crime, não o cidadão!” (25) traduzem, imaginariamente, a voz de um consenso, tendo em vista que o sujeito político assume o lugar discursivo do porta-voz para dar voz aos anseios de um grupo. Assim, apesar de evocar um sentido universalizante, o porta-voz, ao se apresentar como um "nós" inclusivo, dá voz àqueles que se identificam com a posição-sujeito punitivista e se contraidentificam com aquela que é favorável às políticas de direitos humanos, conforme mostramos na análise dessa série de excertos.

\section{Considerações finais}

As análises indicam que os candidatos Cabo Daciolo, José Maria Eymael e Jair Bolsonaro falam em nome do povo, na ilusão de uma totalidade uniforme. Identificamos os pretensos porta-vozes do povo brasileiro falando como um "nós" coletivo, o que se dá pelo uso do pronome "nós", explícito em algumas formulações e elíptico em outras, mas também pelo emprego de outras palavras que indicam coletividade como "cidadãos", "todos", "brasileiros" e "nação brasileira".

Com base no que propõe Zoppi-Fontana (1997), para quem a figura do porta-voz configura-se, no nível do imaginário, como lugar de enunciação coletiva, onde povo e líder são constituídos a partir de uma ilusória relação de interlocução, podemos dizer que a figura enunciativa do porta-voz, identificada na campanha eleitoral de 2018, fala em nome de uma coletividade, mas não em nome da vontade coletiva de um povo brasileiro uno e indiviso, pois a forma de tais candidatos se identificarem com o lugar discursivo do porta-voz aponta 
para a deriva de sentidos (não existe um único porta-voz, mas, como vimos, o porta-voz mensageiro de Deus, o porta-voz mensageiro da justiça, etc.), indicando que essa suposta unidade do "povo brasileiro" é apenas um efeito relacionado à ilusão subjetiva. Assim, ao se constituírem nesse lugar do diferente e sob a ilusão do mesmo, os porta-vozes das campanhas do Cabo Daciolo e José Maria Eymael se identificam com as posições-sujeito: nacionalista, religioso, político, conservador, defensor da família, da Constituição e dos valores morais. O candidato Jair Bolsonaro, por sua vez, se subjetiva nas posições-sujeito: político, conservador, nacionalista, religioso, antipetista, punitivista, defensor de valores morais, anticorrupção.

Ressaltamos que a posição-sujeito agente da mudança, que também configura o lugar do porta-voz, aparece nas três campanhas, entretanto, é constituída a partir da atualização de diferentes memórias e da apresentação de diferentes mundos possíveis. Além disso, a posição-sujeito religioso está materializada na campanha de todos os candidatos, indicando o entrecruzamento do campo religioso com o campo político, sendo que aparece de forma mais acentuada nas campanhas dos candidatos Cabo Daciolo e Jair Bolsonaro, os quais se subjetivam na posição de missionários, mensageiros, como porta-vozes de Deus, na medida em que vinculam suas ações como sujeitos políticos à manifestação da vontade divina.

Por fim, como vimos que o porta-voz é constituído por diferentes posições-sujeito e fala a partir delas, podemos dizer que, em todos os casos analisados, ao ser construída uma ilusão de coletividade, ocorre um silenciamento ${ }^{10}$ daqueles que não se identificam com as posições-sujeito em que o pretenso porta-voz se subjetiva.

${ }^{10}$ Orlandi (2007[1992]) defende que o silêncio pode ser categorizado de duas formas: a) o silêncio fundante, o qual indica que todo processo de significação tem uma relação necessária com o silêncio; b) a política do silêncio (silenciamento), segundo a qual todo dizer, por ser sempre produzido a partir de uma posição-sujeito, necessariamente, cala outros sentidos possíveis. Segundo a autora, esse silenciamento pode ser constitutivo (o não dito necessariamente excluído) e local (manifesta-se pela interdição do dizer). No caso em questão, estamos falando do silenciamento constitutivo, do "mecanismo que põe em funcionamento o conjunto do que é preciso não dizer para poder dizer" (ORLANDI, (2007[1992], p. 74), visto que, ao dizer de um determinado lugar de porta-voz, apaga-se, necessariamente, dizeres de um outro lugar de porta-voz, ao mesmo tempo em que esse não dizer produz sentido. 


\title{
2018 BRAZIL PRESIDENTIAL ELECTION: THE FUNCTIONING OF THE SPOKES- PERSON DISCURSIVE PLACE IN THE CAMPAIGN OF THREE CANDIDATES
}

\begin{abstract}
In this paper, we aim to analyze how are constituted the different subject positions held by three candidates in the 2018 Brazil presidential election, which are affiliated, to some extent, with the religious sphere, indicating which memories these positions bring back. We defend the hypothesis that the spokesperson discursive place works in this case and, therefore, we seek to identify, from the positions through which the said political subjects subdue themselves as candidates for the presidency, how this place is configured in their respective campaigns. To that end, we selected for analysis excerpts of the government plans and publications that these presidential candidates made on the social networks Twitter and Facebook during the election campaign period. After selecting and cataloging the data, we performed a discursive analysis of the materials, based on the theoretical framework of the French Discourse Analysis, mainly in the notions of subject position and spokesperson. The results indicate that, in the discursive event of the 2018 Brazil presidential election, the enunciative figure of the spokesperson, identified in the electoral campaign of the three candidates, despite speaking on behalf of a collectivity, does not represent the will of a unified and undivided Brazilian people. Because the way these candidates identify themselves with the spokesperson discursive place points to the drift of meanings, indicating that this supposed unity of the "Brazilian people" is only an effect related to the subjective illusion.
\end{abstract}

KEYWORDS: Politics; Spokesperson; Subject position; Religion.

\section{REFERÊNCIAS}

INDURSKY, Freda. Lula Lá: estrutura e acontecimento. In: Organon - Revista do Instituto de Letras da UFRGS, Porto Alegre, v. 17, n. 35, p. 102-121, 2003.

LESSA, Alexandre Ribeiro. Memória e discurso político: o discurso religioso e as eleições presidências brasileiras de 2010. Dissertação.114f. (Mestrado em Memória: Linguagem e Sociedade). Universidade Estadual do Sudoeste da Bahia. Vitória da Conquista, 2014.

LOWY, Michael. Conservadorismo e extrema-direita na Europa e no Brasil. Tradução: Deni Alfaro Rubbo e Marcelo Netto Rodrigues. In: Serviço Social \& Sociedade, São Paulo, n. 124, p. 652-664, out./dez. 2015.

ORLANDI, Eni de Lourdes Puccinelli. Análise de Discurso: princípios \& procedimentos. $12^{\mathrm{a}}$ ed. Campinas: Pontes, 2015 [1990].

- As formas do silêncio: no movimento dos sentidos. $6^{\mathrm{a}}$ ed. Campinas, SP: Editora da Unicamp, 2007[1992].

- Interpretação: autoria, leitura e efeitos do trabalho simbólico. $5^{\mathrm{a}}$ ed. Campinas, SP: Pontes Editores, 2007 [1996]. 
PÊCHEUX, Michel. Semântica e discurso: uma crítica à afirmação do óbvio. $5^{\text {a }}$ ed. Campinas: Ed. da Unicamp, 2014 [1975].

. Delimitações, inversões, deslocamentos. Tradução: José Horta Nunes. Cadernos de Estudos Linguisticos, Campinas, IEL/UNICAMP, n.19, p.7-24, jul./dez. 1990 [1982].

O discurso: estrutura ou acontecimento. Tradução: Eni Puccinelli Orlandi. $4^{a}$ ed. Campinas, SP: Pontes Editores, 2008 [1983a].

Só há causa daquilo que falha ou o inverno político francês: início de uma retificação (1978). In: PÊCHEUX, M. Semântica e Discurso: uma crítica à afirmação do óbvio. $5^{\mathrm{a}}$ ed. Campinas: Ed. da Unicamp, 2014 [1975].

- A análise de discurso: três épocas (1983b). In: GADET, Françoise; HAK, Tony (Orgs.) Por uma análise automática do discurso: uma introdução à obra de Michel Pêcheux. Campinas, Ed. da Unicamp, 2014 [1975].

ZOPPI-FONTANA, Monica Graciela. Cidadãos Modernos: discurso e representação política. Campinas, SP. Editora da Unicamp, 1997.

\section{Agradecimentos}

O presente trabalho foi realizado com apoio da Coordenação de Aperfeiçoamento de Pessoal de Nível Superior - Brasil (CAPES). Agradecemos ao Grupo de Pesquisa em Análise de Discurso (GPADis) e ao Programa de Pós-Graduação em Linguística (PPGLin) da UESB.

Recebido em: Aprovado em: 